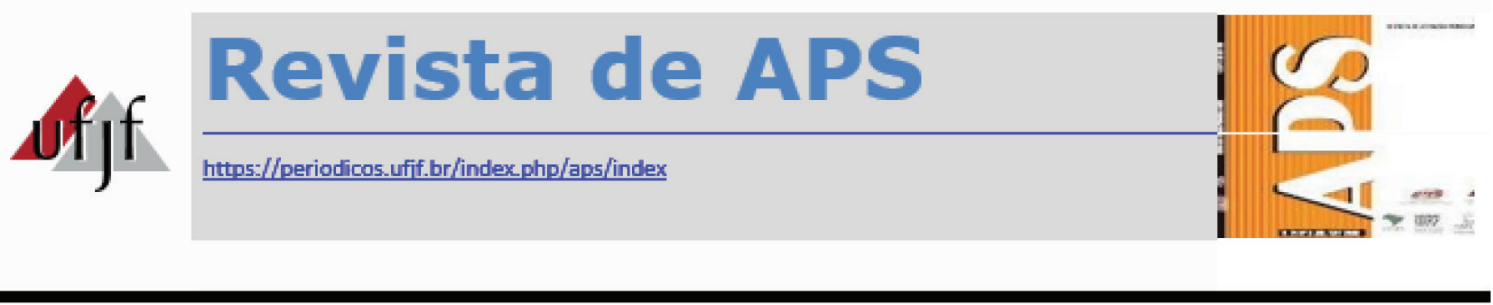

\title{
Depressão entre idosos portadores de doença de Parkinson: opinião dos membros da Associação Capixaba de Parkinson
}

\section{Depression among elderly people with Parkinson disease: opinion of the members of the Capixaba Parkinson Association}

\author{
Hellen Cristina Oliveira Fernandes ${ }^{1}$, Livia Tassinari Scarpat ${ }^{2}$, Marina Miguel \\ de Carvalho ${ }^{3}$, Núbia Dutra de Oliveira ${ }^{4}$, Rebeca Netto Habib Salim ${ }^{5}$, Rodolpho \\ Rodrigues de Souza ${ }^{6}$, Elizabeth Santos Madeira ${ }^{7}$
}

\section{RESUMO}

INTRODUÇÃO: A doença de Parkinson (DP) é a segunda enfermidade neurodegenerativa mais comum no idoso, enquanto a depressão é uma síndrome com transtorno do humor. Os sintomas depressivos são as manifestações não motoras mais comuns entre os acometidos pela DP. OBJETIVO: Demonstrar a percepção que os portadores de DP possuem em relação à depressão e seus sintomas, sendo, para isso, necessário caracterizar as mudanças ocorridas nos hábitos de vida dos portadores de Parkinson, identificar a percepção dos membros da associação sobre os sintomas de depressão e sobre a relação entre DP e depressão, além de caracterizar o convívio social dos portadores de Parkinson com depressão. METODOLOGIA: Estudo descritivo qualitativo, no qual foram entrevistados membros idosos da Associação Capixaba de Parkinson. As entrevistas foram gravadas, transcritas, categorizadas, armazenadas e submetidas à análise de discurso. Este estudo foi aprovado pelo Comitê de Ética da Faculdade Brasileira Multivix sob número 47289215.1.10000.5066. RESULTADOS: O estudo revela que os

\footnotetext{
${ }^{1}$ Faculdade Brasileira de Vitória (Multivix).

${ }^{2}$ Faculdade Brasileira de Vitória (Multivix).

${ }^{3}$ Faculdade Brasileira de Vitória (Multivix).

${ }^{4}$ Faculdade Brasileira de Vitória (Multivix).

${ }^{5}$ Faculdade Brasileira de Vitória (Multivix).

${ }^{6}$ Faculdade Brasileira de Vitória (Multivix).E-mail: rodolpho.phr@gmail.com

${ }^{7}$ Graduada em Medicina e mestra em Atenção à Saúde Coletiva pela Universidade Federal do Espírito Santo, especializada em Saúde Pública pela Universidade de São Paulo e em Epidemiologia pela Escola Nacional de Saúde Pública. Docente do curso de Medicina da Embrae.
} 
diferentes quadros clínicos do Parkinson são definidores dos hábitos de vida desses pacientes, já que causam limitação motora, transtornos do sono e memória, perda da autonomia e desmotivação. Na visão dos membros da Associação Capixaba de Parkinson, os sintomas depressivos são reconhecidos pela maioria dos portadores de Parkinson, que acreditam que há relação entre ambas as doenças. Dessa forma, indivíduos diagnosticados com as duas enfermidades podem ter alterações em seu convívio social, como o isolamento e a busca por grupos de apoio. CONCLUSÃO: O Parkinson gera prejuízos em vários âmbitos da vida do portador, principalmente quando está associado à depressão. Os parkinsonianos reconhecem os sintomas depressivos e percebem a relação com a DP. Aspectos físicos e mentais devem ser levados em consideração no tratamento da doença, necessitando de uma abordagem multiprofissional e interdisciplinar.

PALAVRAS-CHAVE: Depressão. Doença de Parkinson. Idoso.

\section{ABSTRACT}

INTRODUCTION: Parkinson's disease (PD) is the second most common neurodegenerative disease in the elderly while depression is a mood disorder syndrome. Depressive symptoms are non-motor manifestations more common among those affected by Parkinson's disease. OBJECTIVE: To demonstrate the PD patients' perception in regard to depression and its symptoms and, for that, it was necessary to characterize the changes in lifestyle of those affected by Parkinson; to identify the perception of members of the Association about the symptoms of depression and the relationship between PD and depression, in addition, to characterize the social life of Parkinson's patients with depression. METHODOLOGY: Qualitative descriptive study, in which senior members of Parkinson Capixaba Association were interviewed. Interviews were recorded, transcribed, categorized, stored and submitted to discourse analysis. This study was approved by the Faculdade Brasileira- Multivix Ethics Committee No. 47289215.1.10000.5066. RESULTS: The study revealed that Parkinson's different clinical manifestations are definers of the lifestyle of these patients. In the view of members of the Parkinson Association Capixaba, depressive symptoms are recognized by the majority of people with Parkinson's, who believe that there is a relationship between both diseases. Thus, individuals diagnosed with both diseases may have changes in their social life, as isolation and search for support groups. CONCLUSION: Parkinson generates losses in various areas of the person's life, especially when it is associated with depression. Parkinsonians recognize depressive symptoms and perceive its relationship with PD. Physical and mental aspects should be taken into consideration in the treatment of the disease, requiring a multidisciplinary and interdisciplinary approach.

KEYWORDS: Depression. Parkinson Disease. Aged.

\section{INTRODUÇÃO}

A Doença de Parkinson (DP) é considerada a segunda enfermidade degenerativa mais comum no idoso, acometendo cerca de $1 \%$ a $2 \%$ da população com mais de 65 anos. ${ }^{1,2,3,4}$ Por sua vez, a depressão é o transtorno psiquiátrico de maior incidência em pacientes com doença de Parkinson, com uma prevalência estimada de $43 \%$. $^{2,4,5}$ 
Os sintomas não motores na DP, como a depressão, são frequentes. Entretanto, até $50 \%$ desses pacientes não são diagnosticados e tratados. Estudos relatam que até metade dos portadores de DP afirmam que essa disfunção não motora afeta suas atividades diárias significativamente. ${ }^{4}$

Em 1817, James Parkinson descreveu pela primeira vez a DP como uma doença neurodegenerativa, idiopática e multifatorial. ${ }^{1,2}$ Sabe-se que há diminuição da dopamina causada por uma lesão na substância negra do mesencéfalo. Essa redução tem um papel considerável na inibição do controle central dos movimentos. ${ }^{1,2,6}$

O achado mais característico da DP é a presença de corpúsculos de Lewy (inclusões eosinofílicas intracitoplasmáticas) no interior dos neurônios, que pode ser observada no córtex, amígdala, lócus cerúleos, núcleo dorsal do vago e outras áreas. ${ }^{1,2,6}$

As características clínicas da DP manifestam-se quando $80 \%$ da dopamina estriatal e $50 \%$ dos neurônios da substância negra são perdidos. ${ }^{2}$ Os principais sintomas são tremor de repouso, bradicinesia, rigidez e instabilidade postural, que compõem a tétrade clássica. Dois ou mais desses sintomas já caracterizam a DP.,3,4

No estudo de Violante at el, além dos aspectos motores, evidenciou-se que manifestações não motoras, como a depressão, são frequentes e determinantes para acarretarem prejuízos na qualidade de vida dos portadores de DP. ${ }^{3}$

De acordo com o Manual Diagnóstico e Estatístico de Transtornos Mentais, a depressão é caracterizada pela incapacidade de sentir prazer, perda ou diminuição da vontade de realizar as atividades rotineiras, fadiga, sentimento de inutilidade, dificuldade de concentração, insônia, entre outros sintomas. ${ }^{7}$ Os sintomas depressivos são as manifestações não motoras mais comuns entre os acometidos pela DP. ${ }^{1,4}$

O processo patológico da DP pode progredir em seis estágios. No segundo estágio, há grande relação com a depressão já que ocorre comprometimento dos núcleos da rafe, núcleo reticular gigantocelular e do complexo do locus ceruleus. A fisiopatologia da doença não envolve apenas a deficiência exclusiva do sistema dopaminérgico, mas também comprometimento dos sistemas serotonérgicos e noradrenérgicos. Isso explica o surgimento de outros sintomas não motores, como distúrbio do sono, disfunção cognitiva e depressão. ${ }^{8,9}$ Outros sistemas neuronais podem contribuir para a gênese da depressão na DP, porém esses ainda não são muito conhecidos. ${ }^{6}$

Em aproximadamente $25 \%$ dos parkinsonianos deprimidos, a depressão ocorre anteriormente aos sintomas motores da DP. Supõe-se que a "hipótese serotonérgica" seja a possível explicação. Essa hipótese afirma que a baixa atividade de serotonina em cérebros de pacientes com DP é um fator de risco para a depressão. ${ }^{10}$

A serotonina inibe a liberação de dopamina no striatum. Assim, quando há uma redução na atividade da dopamina na DP, ocorre uma redução da atividade da serotonina como mecanismo compensatório. Logo, os parkinsonianos teriam uma vulnerabilidade biológica para transtornos depressivos. ${ }^{10}$ 
Aproximadamente 50\% dos pacientes com DP apresentarão depressão em algum momento da doença. Por outro lado, a depressão pode ser um fator de risco para o desenvolvimento da doença de Parkinson. Dessa forma, a relação entre depressão e DP é complexa e bidirecional, já que uma pode ocasionar a outra. ${ }^{10}$

A depressão pode agravar e trazer consequências problemáticas na evolução da doença de Parkinson. Ela influencia não só a qualidade de vida do paciente, como aumenta os custos diretos e indiretos do tratamento e sobrecarrega ainda mais o cuidador. ${ }^{10}$ Essa influência é agravada pelo quadro de exclusão ao qual o paciente é submetido. ${ }^{11}$

Além disso, a alteração nos hábitos cotidianos dos parkinsonianos pode gerar a depressão devido ao estigma negativo propiciado pela doença. ${ }^{12}$ Por muitas vezes, o aumento do comprometimento motor contribui para esse processo..$^{10,13}$

Muitas contradições marcam o conjunto de estudos sobre DP e depressão. ${ }^{10}$ Isso porque o circuito neuronal entre essas duas doenças não é bem esclarecido, assim como ainda existe incerteza quanto ao diagnóstico e o tratamento. Dessa forma, é notória a necessidade do desenvolvimento de estudos nessa área para contribuir com a adoção de condutas dos profissionais da saúde no desenvolvimento de terapêuticas e práticas clínicas que favoreçam a qualidade de vida dos pacientes.

O objetivo desse estudo foi demonstrar a percepção que os portadores de DP possuem em relação à depressão e seus sintomas, sendo, para isso, necessário caracterizar as mudanças ocorridas nos hábitos de vida dos portadores de Parkinson, identificar a percepção dos membros da Associação Capixaba de Parkinson sobre os sintomas de depressão, identificar a percepção dos portadores de Parkinson sobre a relação entre Parkinson e depressão e caracterizar o convívio social dos portadores de Parkinson com depressão.

\section{METODOLOGIA}

Foi conduzido um estudo descritivo de caráter qualitativo exploratório com membros da Associação Capixaba de Parkinson com DP clinicamente diagnosticada. Essa associação localiza-se em Vitória/ES e possui aproximadamente 250 pacientes, apesar de, por características próprias da doença, serem poucos os que efetivamente têm condições de ser ativistas.

Logo, para a seleção dos participantes da pesquisa, foi utilizada a técnica de identificação de informantes-chaves, entendidos como pessoas que, por sua inserção em um determinado grupo ou comunidade, sejam capazes de representar os pontos de vista da coletividade. Esse é um método de amostragem útil para o estudo de populações difíceis de serem acessadas ou estudadas e trazem como limitação da pesquisa a possibilidade de a coleta de dados refletir as opiniões de uma única vertente sobre o assunto, omitindo diversidades. ${ }^{14}$ 
Assim, o presidente da Associação indicou informantes-chave para responder às entrevistas, levando em consideração a capacidade de compreensão dos mesmos e ter acima de 60 anos. Os que concordaram em participar da pesquisa leram, aceitaram e assinaram o termo de consentimento livre esclarecido. Não houve um limite de entrevistados pré-estabelecido, a inclusão de novos participantes ocorreu até que as informações se tornaram repetitivas, isto é, houve saturação de dados, segundo Minayo. ${ }^{14}$

As oito entrevistas realizadas foram gravadas, transcritas para o programa Microsoft Word, lidas previamente, categorizadas e submetidas à análise de conteúdo do tipo temático. ${ }^{15}$

As variáveis em estudo foram: sexo, idade, escolaridade, estado civil, tempo de diagnóstico da DP, opinião sobre as mudanças ocorridas nos hábitos de vida dos portadores de Parkinson, percepção sobre a depressão, percepção sobre a relação entre DP e depressão e a opinião sobre o convívio social dos portadores de Parkinson com a depressão.

Para a variável percepção sobre a depressão, foi incluída uma breve história simulada de uma paciente com sintomas depressivos clássicos (tristeza, não tinha vontade de sair de casa, tinha dificuldade para dormir e chorava muito) que foi exposta aos sujeitos da pesquisa e, em seguida, foi perguntado o que eles achavam que o paciente apresentava.

O projeto de pesquisa foi apreciado e aprovado pelo Comitê de Ética em Pesquisa da Faculdade Brasileira - MULTIVIX e os aspectos éticos e legais constantes na Resolução do Conep n 466 CNS/MS, de 12 de dezembro de 2012, foram respeitados, tendo sido garantido o anonimato, o sigilo e o direito de desistir de participar sem prejuízo para os sujeitos de pesquisa.

\section{RESULTADOS E DISCUSSÕES}

Participaram desse estudo oito membros da ACP, sendo 5 deles pertencentes ao sexo feminino, média de idade de 68,2 anos e mediana de 68 anos. Quanto à escolaridade, a maioria (5) tinha concluído o segundo grau; eram casados (5) e o tempo de descoberta da doença variou de 4 a 27 anos.

Suas características encontram-se expostas abaixo, entretanto, para resguardar o anonimato, utilizaram-se nomes de ossos devido à grande frequência de quedas e fraturas dentre os portadores de DP entrevistados.

- Senhor Fêmur, masculino, 69 anos, ensino superior completo, casado. $\mathrm{Na}$ descoberta da DP, há 4 anos, sentiu-se assustado e triste.

- Senhora Fíbula, feminino, 71 anos, ensino médio completo, casada. Descoberta da DP há 10 anos, sentiu-se apavorada e surpresa. 
- Senhor Sacro, masculino, 66 anos, ensino médio completo, divorciado. Descoberta da DP há 8 anos, não se sentiu triste nem desanimado.

- Senhora Tíbia, feminino, 75 anos, ensino médio completo, divorciada. Descoberta da DP há 12 anos, não ficou triste e aceitou.

- Senhor Úmero, masculino, 71 anos, mestrado, casado. Descoberta da DP há 6 anos, não se sentiu assustado nem triste.

- Senhor Hioide, masculino, 64 anos, ensino superior completo, viúvo. Descoberta da DP há 22 anos, sentiu-se preocupado.

- Senhora Escápula, feminino, 67 anos, ensino fundamental incompleto, casada. Descoberta da DP há 27 anos, não se importou.

- Senhora Clavícula, feminino, 63 anos, ensino médio completo, casada. Descoberta da DP ha 13 anos, sentiu-se em pânico.

Muitos pacientes entrevistados enfrentaram dificuldades para obter o diagnóstico correto da DP, passaram um longo período de tempo sendo avaliados por diversos médicos antes de serem realmente diagnosticados. Sendo assim, não sabiam precisar há quanto tempo realmente começaram a desenvolver a doença.

"Nós fomos no ortopedista para ter uma ideia, e chegando lá não era nada." (Sr. Fêmur)

“Eu senti um pequeno tremor nas mãos. Eu fui no médico e ele disse que não era nada" (Sra. Fíbula)

"Passei por uma porção de médicos logo no início. Achavam que eu estava com algo parecido com bruxismo, parecia que meus dentes estavam roendo. Só depois resolvi buscar o neurologista porque meu pai já teve Parkinson." (Senhora Tíbia)

"[Os médicos] estavam achando que era o negócio do coagulo, mas não era. [...] Corri mais de uns 20 médicos, fui pro Rio, Belo Horizonte..." (Sra. Clavícula)

"Fui em um [médico] que ele me mandou sentar, pegou o carimbo, bateu na receita com remédio que tinha que tomar, e disse: aqui estar o remédio que senhora tem que tomar. Passou uma vitamina cara que não adiantava nada. Não pediu um exame, nem nada." (Sra. Escápula)

\section{Mudanças ocorridas nos hábitos de vida dos acometidos pelo Parkinson}

As categorias identificadas foram: limitação motora; transtornos do sono; transtornos de cognição; perda da autonomia e desmotivação; redução da interação social; e realização de novas atividades.

A) A vida em ritmo mais lento 
Foram observados prejuízos em vários âmbitos das atividades diárias devido à limitação motora, visto que a doença apresenta múltiplas manifestações clínicas.

"O que bateu foi a limitação de ter que andar de bengala." (Senhor Sacro)

"Há uns 10 anos atrás os sintomas não me atrapalhavam a fazer as atividades da rua que eu gostava, como ir na feira. Agora, de uns tempos pra cá, a perna começou a travar mais." (Senhor Hióide)

"Tenho dificuldade de vestir roupa. Difícil colocar, preciso sentar na cama, mas o pé não levanta com aquele equilibro de antes [...]. Tem que levantar a perna com cuidado." (Senhor Sacro)

"A xícara balança, o café cai, o garfo cai, às vezes suja o chão onde eu estou." (Senhora Fíbula)

"Andei dando empurrão nas pessoas, porque tem hora que falta o freio, tem hora que você quer parar e não consegue, então esbarra nos outros, que te olham estranho." (Senhor Hioide)

Sabe-se que os sintomas motores da DP, como tremor de repouso, rigidez muscular, bradicinesia e instabilidade postural são os principais fatores que causam limitação ou incapacidade dos pacientes, além de serem os sinais clássicos que caracterizam essa doença. ${ }^{16,17}$ Também ocorre diminuição da velocidade dos impulsos nervosos devido ao envelhecimento, gerando alterações nos neurotransmissores como a dopamina, o que causa um controle ineficiente dos movimentos. ${ }^{18}$ Sendo assim, a rapidez e o desembaraço com que as atividades diárias eram executadas dão lugar a passos lentos, às vezes com muito esforço, somado com dificuldade para equilibrar-se, o que foi resumido pelo Senhor Fêmur na seguinte frase:

"Parece que desestabilizou o corpo humano."

Estudos realizados nas cidades de Maringá e Cuiabá (PN) e na cidade de Salvador (BA) também demonstram as dificuldades percebidas no dia a dia dos portadores, o que gera adaptações e mudanças na qualidade de vida. ${ }^{18,19,20}$

"O que mudou mesmo foi que parei de dirigir e algumas atividades de função pública, porque normalmente você tem certas dificuldades, então é difícil você continuar com essas atividades de serviço público. São dificuldades de diç̧ão, de postura, você tem que ser ativo, fluente, e aí não é bom. Aí é melhor continuar com coisas mais tranquilas." (Senhor Úmero)

As dificuldades motoras geram, ainda, como consequência, repercussões no emocional do portador de DP quando se vêm confrontados com suas limitações:

"Quando eu descobri eu entrei em pânico. Quando disse que não podia mais trabalhar, aquilo me deu um pânico tão grande." (Senhora Clavícula)

Dentre outras consequências, nota-se monotonia e pouca articulação na fala, além da caligrafia, que passa a ser menos legível e com tamanho reduzido com o avançar da doença e agravamento dos sintomas motores. ${ }^{21}$ Cerca de $90 \%$ dos portadores da DP 
podem apresentar algum grau de alteração na voz, incluindo comprometimento da produção normal de sons vocais (disfonia) ou problemas com a articulação normal da fala (disartria) que podem comprometer a clareza da mensagem e contribuem para o isolamento social. ${ }^{22,23}$

"Minha assinatura mudou completamente. Escrevo e o banco aceita porque já sabe minha situação, mas mudou." (Senhora Fíbula)

"Eu ainda dava aula, tive que parar porque minha letra começou a ficar ruim. Escrevia no quadro negro e ninguém entendia, além de ter dificuldade para falar." (Senhor Fêmur)

Entretanto, alguns pacientes relatam que o enfrentamento da doença trouxe não apenas experiências negativas. As mudanças trazidas pela DP representaram também crescimento próprio enquanto ser humano, pelas suas necessidades próprias:

"Mudou tudo! O modo de ver a vida. Como pessoa eu melhorei, fiquei mais humana." (Senhora Fíbula)

B) Essa noite que não passa

Os transtornos do sono são alterações comuns nos portadores de DP. Podem ser divididos em primários, cuja causa é degeneração de estruturas cerebrais responsáveis pela fisiologia do sono; e secundários, que são consequências dos problemas motores associados à doença e aos tratamentos da enfermidade. A insônia é o mais frequente dentre os transtornos do sono e está relacionada principalmente com alterações motoras durante a noite. ${ }^{24}$

Dentre outros distúrbios mais comuns, estão: distúrbio comportamental do sono REM, sonolência diurna excessiva, distúrbios respiratórios do sono, síndrome das pernas inquietas e alterações circadianas. Os ciclos interrompidos de sono e vigília contribuem para a baixa qualidade de vida, humor prejudicado, baixo desempenho cognitivo e aumento do risco de acidentes, levando ao aumento da morbidade e mortalidade nessa população. Mesmo assim, os distúrbios do sono são frequentemente ignorados no atendimento clinico dos pacientes com DP. ${ }^{4,25,26}$

"Tudo essa doença atrapalha, até a dormir. Não tenho sossego." (Senhora Escápula)

"Para dormir é mais difícil, porque até para eu virar na cama é complicado." (Senhora Clavícula)

"Ultimamente tenho tido insônia, mas não sei o motivo." (Senhor Fêmur)

C) Do que eu estava falando mesmo? 
Na última década, o déficit cognitivo tem ganhado cada vez mais reconhecimento como parte do espectro de sintomas não motores da DP, apresentando, assim, alto valor no prognóstico e na qualidade de vida dos pacientes. ${ }^{27}$

No entanto, como evidenciadas em recentes revisões bibliográficas de $2014^{28}$ e $2018^{29}$, muitas controvérsias foram geradas sobre esse assunto. As características em comum e a sobreposição de seus fenômenos neuropatológicos da pré-demência (comprometimento cognitivo leve) da demência da doença de Parkinson e da demência de corpos de Lewi tornam os diagnósticos confusos.

"A memória está muito prejudicada por causa do Parkinson. [...] Faço exercícios pra mente [...] porque tô achando que tô decaindo muito. Sinto muita dificuldade nos exercícios, minha cabeça falha. Me perco muito." (Senhora Tíbia)

O perfil clínico do comprometimento cognitivo da DP, assim como nos demais quadros demenciais supracitados, é bastante diversificado e pode afetar áreas como: memória, atenção seletiva e sustentada, cognição visuoespacial, capacidade de construção, especialmente aprendizado e evocação livre, e até mesmo a linguagem, como citado anteriormente. ${ }^{22-27}$

No presente estudo, destacou-se a memória como principal área cognitiva afetada segundo o discurso dos entrevistados. O comprometimento da memória de curto prazo e a memória episódica pareceu estar associado à DP. ${ }^{27,29}$

\footnotetext{
"Piorou minha letra, a falar, a memória. Lembro das coisas para trás, mas o presente é difícil de guardar." (Senhor Fêmur)

"Hoje em dia nem falo mais na igreja, não tenho mais memória. A memória esta muito prejudicada por causa do Parkinson." (Senhora Tíbia)
}

D) Sem disposição para sair sozinho

Há perda da autonomia consequente à limitação motora, fazendo com que os pacientes apresentem dificuldade ao realizarem atividades do cotidiano sozinhos, como por exemplo: vestir-se, tomar banho e passear. Diante dessas situações, surge como consequência a dependência para realizações das suas atividades diárias, nas quais os familiares passam a exercer papel fundamental. Assim, com a progressão da doença e a necessidade de cuidados de outras pessoas, os portadores se veem diante de uma insegurança social. Pela desmotivação que neles se instala, sentem-se, principalmente, cansados e acomodados. Além disso, acreditam incomodar as pessoas à sua volta.

"Eu não saio sozinha, sempre saio com minha família, nem para atravessar a rua. Antes eu viajava sozinha [...]. Os médicos me mandaram muita coisa pra fazer, mas não faço nada, por acomodação." (Senhora Fíbula)

"Ultimamente estou sentindo uma certa indisposição para sair para lugares mais longes, pegar ônibus, andar." (Senhor Sacro) 
"[...] eu me sinto desanimada, cansada, enjoada por causa da doença. E não tenho mais disposição pra congressos da terceira idade, pra igreja [...]. O médico me proibiu de andar de salto alto, e eu adorava [...] fico muito desanimada. Fico triste porque era muito atuante, viajava, passeava, assumia cargos na igreja, mas agora mudou [...]." (Senhora Tíbia)

"Apesar de ainda me virar sozinho, tem muitas coisas que eu dependo de outras pessoas, não vou dizer que eu não dependo porque ai eu estaria mentindo. Então tem hora que dá os problemas que a gente sente logo naquele dia que não está bem. Então você fica desanimado. Você vai para uma festa e não está se sentindo muito bem, aí parece que você já está lá atrapalhando os outros [...]." (Senhor Hioide)

“[...] dentro de casa é pior ainda porque você quer fazer as coisas e não consegue [...]. É difícil de andar, viu? Aí comprei a cadeira (de rodas) pra facilitar um pouquinho, pra não precisar ficar amolando toda hora as pessoas [...]. A gente depende de muita coisa, muita coisa." (Senhora Clavícula)

O Parkinson gera muitas mudanças na estrutura de vida dos pacientes. Assim, as limitações físicas comprometem a capacidade funcional, a realização de atividades profissionais e de lazer. Alguns perdem a motivação e se tornam excessivamente dependentes dos familiares. ${ }^{30}$

Doenças crônicas como o Parkinson reduzem a autoestima de pessoas idosas, que ficam desmotivadas, com perda de prazer, sensação de inutilidade, insatisfação com autoimagem e desânimo. Isso ocorre devido a alterações do estado emocional do paciente. $^{31}$

"Estar doente é muito triste. Pior coisa do mundo é ter doença. Depois que perde a saúde, acabou. A gente não é gente mais, vira um trapo qualquer, não vai para onde quer e é levado para onde o outro quiser." (Senhora Escápula)

\section{E) Unindo forças}

As dificuldades impostas pela doença em realizar as atividades cotidianas causam isolamento social. Em algumas situações a perda de disposição e sentimento de vergonha prejudicam ainda mais o convívio social. ${ }^{32}$

"Não se isolar é importante. Me dou bem com todo mundo. [...] Não ficar se escondendo ajuda." (Senhora Fíbula)

Os grupos de ajuda mútua representam indispensável recurso a ser estimulado nos serviços de saúde, já que auxiliam a preservação da saúde mental da coletividade que vivencia eventos de vida de difícil enfrentamento, como a convivência com a DP. ${ }^{33}$

Por isso, a Organização Mundial de Saúde assim como o Ministério da Saúde estimulam a incorporação dessa modalidade nos programas de educação para o cuidado da saúde, buscando promover a participação nos grupos de convivência, com ações de 
promoção, valorização de vivências positivas e difusão dessas na rede, com intuito de captar e compartilhar experiências. ${ }^{33,34}$

"Mas foi bom ter a associação porque me encorajou ir nas reuniões. Surgiram cursos e você vai conhecendo as pessoas. Mas eu também assumi que tinha Parkinson e tive que enfrentar. Comecei a observar que tinham várias pessoas que eu conhecia que tinha Parkinson e comecei a falar para elas procurarem a associação. E eles negavam, tinham gente que tinha e negava. É melhor assumir do que negar." (Senhor Fêmur)

"Lá [na associação capixaba de Parkinson] eu passava umas horas melhores, né? Porque fico presa dentro de casa sozinha." (Senhora Clavícula)

"Na associação eu faço fisioterapia. Gosto muito de lá! Quando volto de lá, venho melhor. As pessoas de lá tratam a gente muito bem. Converso com todo mundo da associação." (Senhora Escápula)

Além disso, a ajuda de amigos e participação em grupos comunitários foram citados como fatores de convívio social que proporcionam um bem-estar aos portadores de DP. Assim, a preservação das relações sociais com o cônjuge, familiares e amigos da mesma geração são fatores benéficos. ${ }^{35}$

"Faço parte até do conselho da associação de moradores do bairro, fui eu que fundei também. Continuo nessas atividades para não perder o contato com as coisas, com o estímulo de viver." (Senhor Úmero)

"Amigos ajudam. Amigos do novo ciclo de relacionamento, os amigos da praia. Me levam de carro, me ajudam, querem bem, perguntam o que eu quero." (Senhor Sacro)

\section{F) A busca por novos hábitos}

Ao contrário do estereótipo criado para pessoas com DP, muitos entrevistados relataram a aprendizagem e realização de novas atividades ou o reforço daquelas que já praticavam. Dessa forma, nota-se a disposição dos pacientes na busca por uma ocupação para enfrentarem as limitações naturais dessa doença.

"Comecei a fazer flores mesmo. Já fazia, né? Aí aumentei mais, comecei a fazer pra vender mesmo. Pra poder passar o tempo e ver se eu melhorava." (Senhora Escápula)

"Minha fuga era trabalhar. Hoje continuo fazendo bordado, crochê. Mas minha mão tá sem jogo, não consigo segurar. Mas já tô arranjando um jeito, eu tento de todo jeito." (Senhora Tíbia)

"Sou convidado a participar das associações, criei a associação de moradores e participo por vontade própria, tenho um certo compromisso com ela ainda e gosto. Tem que ter seu tempo bastante ocupado." (Senhor Úmero) 
Visando retardar e minimizar a evolução da DP, o tratamento fisioterapêutico torna-se essencial desde o início da doença, almejando melhorar a realização de atividades da vida diária. ${ }^{36}$

Estudos mostram que a falta de atividade física facilita a atrofia muscular, o que gera aumento na rigidez típica do parkinsoniano. ${ }^{37}$

Deste modo, por meio da prática de exercícios adequados para o aumento da força muscular, pode-se influenciar positivamente no equilíbrio desses pacientes, o que evita as quedas, muito comuns na DP. Além disso, a abordagem motora constante promove a ativação de neurotransmissores, como a serotonina, e reduz os sintomas psiquiátricos. $^{38,39}$

"Faço 3 vezes por semana pilates, 2 vezes fisioterapia, 2 vezes RPG e 1 vez acupuntura. Vejo os resultados na luta contra a rigidez, e a cada dia que passa terei que aumentar a dose." (Senhor Fêmur)

Outro tipo de atividade fundamental referida é a fonoaudiologia. A maximização da mobilidade e da amplitude dos movimentos exercidos nessa atividade melhora a agilidade articulatória e o ritmo, além de adequar a velocidade da fala. Além disso, exercícios de respiração na fonoaudiologia melhoram a coordenação fonoarticulatória sobre a característica da voz monótona ou com frequência e intensidade diminuídas. ${ }^{40}$

"Você tem que respeitar os médicos, respeitar o que eles passam, tomar os comprimidos de acordo com o que eles passam, fazer os exercícios. [...] Eu faço hidroginástica, faço pilates, faço fonoaudiologia e faço musculação. Então tenho bastante atividade." (Senhor Úmero)

\section{Percepção dos membros da Associação Capixaba de Parkinson sobre os sintomas de depressão}

Para esse objetivo foram identificadas as seguintes categorias: identificação da depressão; falta de conhecimento sobre depressão.

A) Uma tristeza profunda

Ao serem apresentados a um caso clínico de uma paciente com sintomas depressivos clássicos, muitos dos pacientes perceberam imediatamente a depressão ou reconheceram parte dos seus sintomas depressivos.

"Talvez ela [paciente] está passando por um processo depressivo. Talvez ela não esteja recebendo a devida atenção pela família, esteja com algum problema de doença mesmo, doença depressiva. " (Senhor Úmero) 
“Depressão. Às vezes ela [paciente] não tem ninguém que a ajude, sem ajuda de ninguém, né? Sozinha dispara a chorar, pensando que podia fazer isso, mas não pode. " (Senhora Clavícula)

B) O que é essa tal depressão?

A maioria dos entrevistados reconheceu a depressão quando apresentados ao quadro clínico fictício no decorrer da entrevista, indo de encontro ao estudo de Survey ${ }^{41}$ que relatou que poucos pacientes souberam reconhecer sintomas, apesar da alta prevalência da depressão entre aqueles que possuem DP.

"Acho que dona Maria (personagem do caso) está se isolando, entristecida. E eu acho que eu estou assim como ela. Não estou mais como antes com aquele ânimo todo." (Senhora Tíbia)

"Não consegue colocar alegria nenhuma na vida dela, não tem mais condição nessa situação. E pra ela sair dessa, ela tem que pegar em um pedacinho de prazer em alguma coisa pra ela pegar o fio da meada e voltar a juntar." (Senhor Sacro)

Entretanto, alguns pacientes não possuem informação sobre a depressão, apesar de ser direito do paciente o acesso às informações sobre os seus problemas de saúde, diagnóstico, tratamento, prognóstico, e o repasse dessas informações ser de competência de toda a equipe de saúde..$^{42}$

"Eu não sei [o que a paciente tem]. Porque cada um pensa de um jeito. Essa história de depressão eu não sei o que é [...]." (Senhor Hioide)

"A dor que eu sentia no peito há muito tempo atrás era da depressão. Era uma tristeza tão grande que eu não aguentava. Eu não sabia o porquê de eu tinha essa tristeza." (Senhora Clavícula)

\section{Percepção dos portadores de Parkinson sobre a relação entre DP e depressão}

Com o intuito de avaliar o conhecimento dos portadores acerca da relação entre DP e depressão, foi indagado se observaram exemplos semelhantes aos do caso clínico apresentado dentre os membros da ACP. Os entrevistados conseguem perceber uma alta frequência de depressão entre os portadores de DP.

"Isso [sintomas depressivos] é muito frequente entre os portadores, ficam muito tristes. Se curvam muito, as pessoas logo reconhecem [...]." (Senhora Fíbula)

"Essa situação [depressão] é frequente nos doentes de Parkinson. Chego lá [na Associação Capixaba de Parkinson] e vejo umas caras tristes." (Senhora Tíbia)

"Eu tenho participado de reuniões na Associação de Parkinson e, às vezes, você encontra pessoas muito paradas, muito sem estímulo de viver. Então eu acho que seja uma indicação da depressão." (Senhor Úmero) 
A prevalência de depressão ocorre em $50 \%$ dos pacientes com DP, o que corrobora a percepção dos portadores entrevistados. ${ }^{10}$

Muitos exemplificaram a depressão entre portadores de Parkinson conhecidos.

Relataram casos de desânimo e desespero, associando tais sintomas à depressão.

"Eu tinha um amigo aqui na rua que tinha Parkinson, ele ficava com a cara séria e eu perguntava 'o que houve?', ele me perguntava 'você está rindo de que, se nós temos Parkinson?' e ele falava 'não tem cura'. Mas eu falava: 'eu tô vivo ainda, rapaz. Enquanto eu tiver vivo eu vou levando, empurrando com a barriga. Isso aí a gente vai ver como fica depois. Não dependo só disso para rir."' (Senhor Hioide)

"Eu conheci um rapaz quando eu fazia fisioterapia [...]. Ele tinha depressão muito profunda porque ele é muito mais novo do que eu. Tinha 39 anos, se não me engano. A mulher separou dele por causa da doença, foi abandonado pela mulher. Ele entrou em desespero, era depressão." (Senhora Clavícula)

"Imagina você querer tomar um banho e não poder, não conseguir [...]. Então entra em parafuso mesmo, os neurônios parecem que te deixam em desespero. Acho que isso é depressão." (Senhora Clavícula)

Acredita-se que a depressão possui dois picos, o primeiro imediato ao diagnóstico e o segundo nos últimos estágios da DP, relacionado à diminuição das atividades da vida diária. ${ }^{4}$ Sintomas como perda de peso, alterações no sono e apetite, perda de interesse e concentração, comprometimento da memória e redução da libido são comuns tanto em pacientes com depressão quanto na DP, havendo uma sobreposição de sintomas. ${ }^{8}$

\section{Convívio social dos portadores de Parkinson com depressão na visão dos membros da Associação Capixaba de Parkinson}

Ao analisar o convívio social dos portadores de DP com depressão, evidenciaramse duas categorias: necessidade de apoio; necessidade de interação.

\section{A) Não sou nada sem você}

Os membros da Associação perceberam a relação dos benefícios que o apoio de amigos e familiares gera aos pacientes com DP e depressão. Muitos portadores de DP acreditam que esse auxílio é fundamental para evitar sintomas depressivos.

"Acho que o apoio da família em tudo é importante, até mesmo se não for família. Qualquer pessoa que te apoie, até mesmo quando você não está precisando é bom. Um sorriso é melhor do que certas coisas." (Senhor Hioide)

"Minha família me ajudou, ajuda até hoje. Tenho uma boa relação com meus filhos, não tenho motivo pra ter depressão. Meus amigos me ajudaram." (Senhor Sacro)

"Acho que se a pessoa não tiver o apoio da família, não continuar em algumas atividades, pode transformar em depressão. No meu caso, o apoio da família conta muito, sem dúvida." (Senhor Úmero) 
De acordo com a literatura, o apoio dos familiares e amigos, principalmente os que assumem o papel de cuidadores, é fundamental para os portadores de depressão e Parkinson. Sabe-se que a depressão em pacientes com DP é um fator determinante para sobrecarga desses cuidadores. Entretanto, quem cuida precisa manter-se tranquilo, pois o estresse afeta diretamente a saúde dos pacientes. ${ }^{43}$

B) Compartilhando experiências

Para os entrevistados, os portadores de Parkinson e depressão podem ter seus sintomas reduzidos ao interagirem com outras pessoas, principalmente com outros pacientes que possuem as mesmas doenças.

"Sempre tinha um triste [na Associação Capixaba de Parkinson]. Aí a turma ajudava, conversava e ele melhorava." (Senhora Clavícula)

"Pelo que eu sei, a maioria [dos portadores de DP] tem uma pequena depressão, mas se der muito, tem que tomar cuidado. Mas estar em contato com outros portadores é muito importante. Participar das reuniões da associação é bom, principalmente para esclarecer a doença e para pessoa perceber que não é só você que tem problema. Tem gente muito pior que você. Você precisa ter apoio, principalmente da família." (Senhor Fêmur)

"Eu acho que participar desses encontros e conviver com pessoas com a mesma doença, se não fizer bem, mal não faz." (Senhor Hioide)

"O convívio com outros portadores melhora muito. A gente brinca bastante, rimos do que temos." (Senhor Sacro)

"Sair de casa melhora muito meu ânimo, sair com os netinhos [...]. " (Senhora Tíbia)

Um estudo realizado com 13 participantes concluiu que o convívio social afeta diretamente o estado mental, o humor e o bem-estar do paciente. ${ }^{38}$ Dessa forma, a ampliação das redes sociais dos portadores de Parkinson depressivos é fundamental para melhora dessas enfermidades. ${ }^{44}$

\section{CONSIDERAÇÕES FINAIS}

Este estudo refletiu dados da literatura existente de que a depressão acomete frequentemente o portador de DP, decorrente às características inerentes da doença que propiciam queda na qualidade de vida pela limitação motora, alterações na fala e na escrita, distúrbios do sono, perda da autonomia, diminuição da autoestima, isolamento social.

Sendo a depressão uma comorbidade que pode acelerar a progressão da DP e ambas as doenças podem levar a piora do quadro clínico, é importante que 
os portadores de DP, assim como seus cuidadores e sua equipe de saúde, saibam reconhecer os sintomas depressivos para que possa ser instituído o tratamento precoce e adequado a fim de impedir a deterioração clínica que a sobreposição dessas comorbidades possa acarretar.

A abordagem da depressão, assim como da DP, exige uma equipe multiprofissional e interdisciplinar. Todas as suas particularidades devem ser levadas em consideração, já que influenciam negativamente no quadro do paciente - prejuízo no convívio social, desmotivação, alterações no sono e memória. A saúde mental é tão relevante quanto os sintomas físicos na evolução da DP, motivo pelo qual não deve ser negligenciada por quem a sente ou por quem a observa.

Sendo assim, devido ao grande prejuízo social e funcional que os sintomas da depressão causam nos portadores da DP, é fundamental um maior preparo da equipe de saúde para essa abordagem global do paciente. Nesse contexto, deve-se incluir a oferta de informações suficientes para que os próprios portadores de DP reconheçam seus sintomas depressivos, facilitando o diagnostico da depressão e a adoção de uma melhor propedêutica. Além disso, devem ser oferecidas medidas efetivas para uma melhoria nas atividades diárias desses pacientes, que por sua vez contribuem para prevenir a depressão.

O Brasil possui programa público de saúde voltado para os portadores de DP mais focado no fornecimento gratuito de medicações, tanto as de alto custo quanto aquelas fornecidas nas unidades básicas de saúde. Entretanto, é necessário torná-lo mais abrangente, garantindo reabilitação motora, suporte psicológico e social. Sendo assim, grupos operativos e mais associações destinadas à DP contribuiriam para promover a inclusão dos portadores em redes sociais próximas a eles. Logo, uma vez que o convívio com pessoas que passam por situações semelhantes; o incentivo à realização de novas atividades dentro das limitações impostas pela doença; a prática de fisioterapia, fonoaudiologia e atividades físicas; e o apoio de familiares e amigos são pilares reconhecidos para a redução dos sintomas depressivos e diminuição da progressão dos sintomas motores da DP, tais atividades devem ser empregadas para que a manutenção da qualidade de vida desses pacientes seja obtida como consequência.

É importante que a equipe de saúde perceba a relação entre DP e depressão e esteja apta para receber os pacientes e instruir suas famílias e cuidadores sobre os diversos aspectos de ambas as doenças. Assim, uma rede de atenção integral estruturada a partir da atenção básica de saúde, principalmente no âmbito da Estratégia Saúde da Família, com conexões com os níveis secundários e terciários da atenção, é hoje a medida mais efetiva na resolução das dificuldades vivenciadas pelos portadores de DP, de forma que possa ser cumprido o princípio da integralidade do Sistema Único de Saúde. 


\section{REFERÊNCIAS}

1. Sertão AT, Ferreira DAS. Relação entre estilo de vida e a etiologia da doença de Parkinson em pacientes do Município de Jequié BA. Rev Bras Neurol. 2018 out; 54(4):12-18.

2. Correia MGS, da Paixão AO, de Jesus AVF, Silva FS, Messias GMS, Nunes TLGM, et al. Doença de Parkinson: uma desordem neurodegenerativa. Caderno de Graduação Ciências Biológicas e da Saúde - UNIT. 2013 fev; 1(2):57-65.

3. Violante MR, Ordonez AC, Arriga C, Latapi PG, Osuma V.Factores associados a la calidad de vida de sujetos com enfermedad de Parkinson y a la carga em el cuidador. Neurología. 2015 jun; 30(5):257-63.

4. Arriaga AC, Violante MR. Disfunción no motora en la enfermedad de Parkinson: una enfermedad neurológica con manifestaciones multisistémicas. Med Int Mex. 2011; 27(1):29-37.

5. Ikuta YM, Reis CRM, Ramos MMAB, Borges MMG, Araújo MC. Avaliação da função cognitiva em pacientes com doença de Parkinson. Rev para Med. 2012 mar; 26(1).

6. Cardoso EF. Avaliação do tratamento de depressão em pacientes com doença de Parkinson através de ressonância magnética funcional. Radiol Bras. 2009 abr; 42(2):108.

7. Diagnostic and Statistical Manual of Mental Disorders. DSM - V. Americana Psychiatric Association; 2013.

8. Souza CFM, Almeida HCP, Sousa JB, Costa PH, Silveira YSS, Bezerra JC. A doença de Parkinson e o processo de envelhecimento motor: uma revisão de literatura. Rev de Neuroc. 2011 jan; 19(4):718-23.

9. Oliveira, MDD, Machado, DMS. Declínio cognitivo na Doença de Parkinson: contribuições da neuropsicologia. Rev Med Minas Gerais. 2014; 24(3):349-54.

10. Silberman CD, Laks J, Rodrigues CS, Engelhardt E. Uma revisão sobre depressão como fator de risco na Doença de Parkinson e seu impacto na cognição. Ver Psiquiatr RS. 2004 abr; 26(1):52-60.

11. Christofoletti G, Formiga CKMR, Borges G, Stella F, Damasceno BP. Aspectos físicos e mentais na qualidade de vida de pacientes com doença de Parkinson idiopática. Fisioter Pesqui. 2009 mar; 16(1):65-9.

12. Margis R, Donis KC, Schönwald VS, Rieder CRM. WhOQOL-OLD assessment of quality of life in elderly patients with Parkinson's disease: influence of sleep and depressive symptoms. Rev Bras Psiquiatr. 2010 jun; 32(2):125-31.

13. Galhardo MMAMC, Amaral AKFJ, Vieira ACC. Caracterização dos distúrbios cognitivos na doença de Parkinson. Revista CEFAC.2009; 11(2):251-7. 
14. Minayo MCS. O desafio do conhecimento: pesquisa qualitativa em saúde. 13a edição. São Paulo: Hucitec; 2013.

15. Bardin L.Análise de conteúdo. São Paulo: Edições 70; 2016.

16. Postuma RB, Berg D, Stern M, Poewe W, Olanow CW, Oertel W, et al. MDS clinical diagnostic criteria for Parkinson's disease. Mov Disord. 2015 Oct; 30(12):1591-601.

17. Moreira RC, Zonta MB, Araújo APS, Israel VL, Teive HAG. Quality of life in Parkinson's disease patients: progression markers of mild to moderate stages. Arq Neuro-Psiquiatr. 2017 Aug; 75(8):497-502.

18. Burke RE. Evaluation of the Braak Staging Scheme for Parkinson's disease: Introduction to a Panel Presentation. Mov Disord. 2010; 25(1):76-7.

19. Navarro- Peternella FM, Marcon SS. A convivência com a doença de Parkinson na perspectiva do parkinsoniano e seus familiares. Rev Gaúcha Enferm. 2010 set; 31(3):415-422.

20. Pinheiro IM, Santos LLS, de Paula LCN, Costa ACN. Impacto da Doença de Parkinson na funcionalidade e qualidade de vida de idosos em uma unidade de referência geriátrica na cidade de Salvador - Bahia. Rev Ciênc Méd Biol. 2014 set-dez; 13(3):292-7.

21. Pereira CR, Pereira DR, Rosa GHR, Albuquerque VHC, Weber SAT, et al. Handwritten dynamics assessment through convolutional neural networks: An application to Parkinson's disease identification. Artif Intell Med. 2018 May; 87:67-77.

22. Vizza P, Tradigo G, Mirarchi D, Bossjo RB, Lombardo N, Arabia G, et al. Methodologies of speech analysis for neurodegenerative diseases evaluation. Int J Med Inform. 2019 Feb; 122:45-54.

23. A Little Max, et al. Suitability of Dysphonia Measurements for Telemonitoring of Parkinson's Disease. EEE Trans Biomed Engineering. 2009 Apr; 56(4):1015-22.

24. Clavero P, Rodríguez-Oroz MC. Trastornos del sueño en la enfermedad de Parkinson y otros trastornos del movimiento. Anales Sis San Navarra. 2007; 30(1):143-53

25. Videnovic A. Management of sleep disorders in Parkinson's disease and multiple system atrophy: Sleep in PD and MSA. Mov Disord. 2017 May; 32(5):659-68.

26. Iranzo A, Silber MH. Stop, look, and listen: sleep in movement disorders. Mov Disord. 2017 May; 32(5):633-63.

27. Goetz CG, Emre M, Dubois B. Parkinson's disease dementia: definitions, guidelines, and research perspectives in diagnosis. Ann Neurol. 2008 Dec; 64(2):81-92.

28. Goldman JG, Williams-Gray C, Barker RA, Duda JE, Galvin JE. The spectrum of cognitive impairment in Lewy body diseases. Mov Disord. 2014 Apr; 29(5):608-21. 
29. Das T, Hwang JJ, Poston KL. Episodic Recognition Memory and the Hippocampus in Parkinson's disease: A review. Cortex. 2018 Dec; 113(4):191-209.

30. Almeida MHM, Castiglioni MC. Recursos tecnológicos: estratégia de promoção do autocuidado, atividades e participação para pessoas com doença de Parkinson. Rev Ter Ocup. 2007 Set-Dez; 18(3):152-7.

31. Moreira RCPS. Impacto da doença de Parkinson na qualidade de vida de indivíduos nas fases leve e moderada [dissertação]. Curitiba: Universidade Federal do Paraná, Programa de Pós-Graduação em Medicina Interna, Setor de Ciências da Saúde; 2014.

32. Magalhães NPF, Silva SM. Uma convivência com a doença de Parkinson na perspectiva do parkinsoniano e seus familiares. Rev Gaúcha Enferm. 2010 set; $31(3): 415-22$.

33. Gonçalvez LHT, Alvarez AM, Arruda MC. Pacientes portadores da doença de Parkinson: significado de suas vivências. Acta Paul Enferm. 2007; 20(1):62-8.

34. BRASIL. Portaria no 2528, de 19 de outubro de 2006. Aprova a Política Nacional de Saúde da Pessoa Idosa. Diário Oficial da Republica Federativa do Brasil.

35. Carneiro RS, Falcone E, Clark C, Del Prette Z, Del Prette A. Qualidade de vida, apoio social e depressão em idosos: relação com habilidades sociais. Psicologia: reflexão e crítica. 2007; 20(2):229-37.

36. Haase DCBV, Machado DC, Oliveira JGD. A atuação da fisioterapia no paciente com Doença de Parkinson. Fisioter Mov. 2008 jan-mar; 21(1):79-85.

37. Steidl EMS, Ziegler JR, Ferreira FV. Doença de Parkinson: revisão bibliográfica. Disc Scientia. 2007; 8(1):115-29.

38. Christofoletti G, Cândido ER, Olmedo L, Miziara SRB, Beinotti F. Efeito de uma intervenção cognitivo-motora sobre os sintomas depressivos de pacientes com doença de Parkinson. J Bras Psiquiatr. 2012 jan; 61(2):78-83.

39. Rodrigues-de-Paula F, Lima LO, Teixeira-Salmela LF, Cardoso F. Exercício aeróbio e fortalecimento muscular melhoram o desempenho funcional na doença de Parkinson. Fisioter. Mov. 2011 set; 24(3):379-88.

40. Palermo S, Bastos ICC, Mendes MFX, Tavares EF, dos Santos DCL, Ribeiro AFC. Avaliação e intervenção fonoaudiológica na doença de Parkinson. Análise clínicaepidemiológica de 32 pacientes. Rev Bras Neurol. 2009 out; 45(4):17-24.

41. The Global Parkinson's Disease Survey Steering Committee. Factors impacting on quality of life in Parkinson's disease: results from an internacional survey. Mov Disord 2002 Jan; 17(1):60-7. 
42. Ministério da Saúde (BR). Carta dos direitos dos usuários da saúde. Brasília: Ministério da Saúde, 2007.

43. Benavides $O$, Alburquerque D, Chaná-Cuevas P. Evaluación de la sobrecarga en los cuidadores de los pacientes con enfermedad de Parkinson ambulatorios y sus factores de riesgo. Rev Med Chile.2013 Mar; 141(3):320-6.

44. States RA, Spierer DK, Salem Y. Long-term group exercise for people with Parkinson's disease: a feasibility study. J Neurol Phys Ther. 2011 Sep; 35(3):122-8.

Submissão: maio de 2016.

Aprovação: maio de 2019. 